JAMP: Jurnal Adminitrasi dan Manajemen Pendidikan

Volume 4 Nomor 1 Maret 2021, Hal : 32 - 40

Tersedia Online di http://journal2.um.ac.id/index.php/jamp/

ISSN 2615-8574 (online)

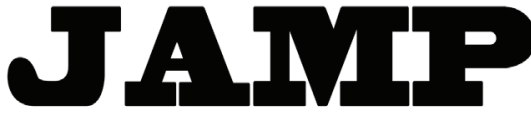

JURNAL ADMINISTRASI DAN MANAJEMEN PENDIDIKAN

\title{
PENGARUH CONSUMPTION ABROAD DAN PERKEMBANGAN TEKNOLOGI TERHADAP PERUBAHAN KEPEMIMPINAN STRATEGIS PENDIDIKAN TINGGI
}

\author{
Teguh Triwiyanto ${ }^{1}$ \\ Junaidin ${ }^{2}$ \\ Asmaa Abusamra $^{3}$ \\ ${ }^{1}$ Universitas Negeri Malang, Indonesia \\ ${ }^{2}$ Lembaga Penjaminan Mutu Pendidikan Provinsi Kalimantan Tengah \\ ${ }^{3}$ The University College of Applied Science, Gaza, Palestine \\ Email: teguh.triwiyanto.fip@um.ac.id
}

\begin{abstract}
Consumtion abroad is one of the real impacts of globalization, there is a movement of consumers going abroad and have non-resident status where services are consumed, including higher education. In Indonesia, economic growth is influenced by the level of education and technology, both of which converge in the classroom teaching and learning. Higher education has a strategic role to play in meeting education and technology in the teaching and learning classroom. The factors of knowledge and power, domestic politics, in education have a lot of influence on the development direction of this strategic field. Considered and careful strategic leadership, preserving distinctiveness, and promoting equality among cultures are the long-term commercial interests of higher education, as well as offering individual and social benefits.
\end{abstract}

Keywords: Consumption Abroad; technological developments; changes in strategic leadership.

\begin{abstract}
Abstrak: Consumtion abroad merupakan salah satu dampak globalisasi yang nyata, terjadi arus perpindahan konsumen pergi ke luar negeri dan berstatus bukan penduduk dimana jasa dikonsumsi, termasuk pendidikan tinggi. Di Indonesia, pertumbuhan ekonomi dipengaruhi oleh tingkat pendidikan dan teknologi, keduanya bertemu di dalam kelas pengajaran dan pembelajaran. Pendidikan tinggi memiliki peran strategis terhadap pertemuan pendidikan dan teknologi dalam kelas pengajaran dan pembelajaran tersebut. Faktor-faktor pengetahuan dan kuasa, politik domestik, dalam pendidikan banyak memberikan pengaruh terhadap arah pengembangan bidang strategis tersebut. Kepemimpinan strategis yang dipertimbangkan dan berhati-hati, menjaga kekhasan, dan mempromosikan kesetaraan di antara budaya adalah kepentingan komersial jangka panjang dari pendidikan tinggi, serta menawarkan manfaat individu dan sosial.
\end{abstract}

Kata kunci: Consumption abroad; perkembangan teknologi; perubahan kepemimpinan strategis.

Globalisasi telah mendorong berbagai pendidikan tinggi di berbagai negara untuk terus meningkatkan tata kelola berkompetisi dalam banyak berbagai layanan akademik. Saat ini peran emerging economies mencapai $71 \%$ dari total output dunia dan perdagangan internasional tumbuh $3.4 \%$. Penduduk dunia saat ini 9.45 milyar, $65 \%$ penduduk hidup di perkotaan, dan terjadi pergeseran mata uang dari dolar AS menjadi multi currencies. Oude Vrielink et al., (2019) menyatakan perkembangan kebijakan pendidikan di dunia tampak pada tiga model berikut: (1) Model yang berpusat pada negara; pendidikan tinggi dilihat sebagai lembaga yang dioperasikan oleh negara; (2) Perguruan Tinggi sebagai komunitas yang mengatur diri sendiri, adalah model yang didasarkan pada kemitraan universitas-negeri yang kuat, yang diatur oleh asumsi korporatisme dan kesepakatan bersama; dan (3) Sifat berorientasi pasar. 
Tahun 2018, Indeks Pembangunan Manusia Indonesia mencapai 71.39, meningkat sebesar 0.58 dari tahun sebelumnya. Tahun 2018 merupakan tahun ketiga Indonesia berstatus pembangunan manusia "tinggi" dengan Umur Harapan Hidup saat lahir mencapai 71.20 tahun. Ini berarti bahwa bayi yang baru lahir dapat bertahan hidup hingga usia 71.20 tahun. Secara rata-rata, penduduk Indonesia usia 25 tahun ke atas sudah menempuh 8.17 tahun masa sekolah atau telah menyelesaikan pendidikan setara kelas VIII. Selain itu, rata-rata penduduk usia 7 tahun yang mulai bersekolah, diharapkan dapat mengenyam pendidikan hingga 12,91 tahun atau setara dengan Diploma I. Tidak kalah penting, standar hidup layak Indonesia yang diwakili oleh indikator pengeluaran per kapita yang disesuaikan sudah mencapai US\$ 3.92 per kapita per tahun.

Untuk mengukur kualitas pendidikan tinggi secara keseluruhan, salah satunya dapat diketahui dari pemeringkatan pada QS University Ranking. Kualitas pendidikan tinggi dievaluasi sesuai dengan enam metrik yaitu reputasi akademik (40\%), reputasi employer (10\%), rasio fakultas / mahasiswa (20\%), kutipan per fakultas $(20 \%)$, rasio fakultas internasional, dan rasio mahasiswa internasional (5\% each). Sistem pemeringkatan ini sering digunakan dan banyak dirujuk di tingkat global. Tabel 1 berikut ini diuraikan hasil yang diraih pendidikan tinggi di Indonesia dari sistem pemeringkatan tersebut.

Tabel 1. Indonesia dalam QS World University Ranking 2014-2019

\begin{tabular}{ccccccccc}
\hline Tahun & UI & ITB & UGM & IPB & UNAIR & UB & UNDIP & UNPAD \\
\hline 2014 & 309 & $461-470$ & $501-550$ & $701+$ & $701+$ & $701+$ & $701+$ & \\
2015 & 310 & $461-470$ & $551-600$ & $701+$ & $701+$ & $701+$ & $701+$ & \\
2016 & 358 & $431-440$ & $551-600$ & $701+$ & $701+$ & $701+$ & $701+$ & \\
2017 & 325 & $401-410$ & $501-550$ & $701+$ & $701+$ & $701+$ & $701+$ & \\
2018 & 277 & 331 & $401-410$ & $751-1000$ & $701-750$ & $801-1000$ & $801-1000$ & \\
2019 & 292 & 359 & 391 & $701-1000$ & $751-800$ & $801-1000$ & $801-1000$ & $651-700$ \\
\hline
\end{tabular}

QS Asia University Ranking, pada kategori ini, pemeringkatan hanya dilakukan terhadap perguruan tinggi di Asia meskipun mencakup sebagian saja yang berasal dari 17 negara. Indikator yang digunakan untuk menyusun Peringkat Universitas QS Asia yaitu reputasi akademik (30\%), reputasi pemberi kerja $(20 \%)$, rasio fakultas / mahasiswa $(10 \%)$, jaringan penelitian internasional $(10 \%)$, kutipan per makalah $(10 \%)$ dan makalah per fakultas $(5 \%)$, staf dengan gelar phd $(5 \%)$, proporsi fakultas internasional $(2,5 \%)$ dan proporsi mahasiswa internasional $(2,5 \%)$, dan proporsi mahasiswa pertukaran masuk $(2,5 \%)$ dan proporsi mahasiswa pertukaran keluar $(2,5 \%)$. Berdasarkan pemeringkatan di tingkat Asia ini, pendidikan tinggi Indonesia menunjukkan kinerja yang positif pada periode 2015-2019 melalui peningkatan peringkat yang kontinu. Tabel 2 memperlihatkan pemeringkatan dari QS Asia University Ranking untuk perguruan tinggi terkemuka lainnya di Indonesia 2015-2018.

Tabel 2. Indonesia dalam QS Asia University Ranking 2015-2018

\begin{tabular}{ccccccccc}
\hline Tahun & UI & ITB & UGM & IPB & UNAIR & UNPAD & UNDIP & UB \\
\hline 2015 & 71 & 125 & 145 & $201-250$ & 127 & $201-250$ & $201-250$ & $251-300$ \\
2016 & 79 & 122 & 137 & $201-250$ & 147 & $161-170$ & $251-300$ & - \\
2017 & 67 & 86 & 105 & 191 & 190 & 199 & $231-240$ & $301-350$ \\
2018 & 54 & 65 & 85 & 147 & 171 & 176 & 240 & $291-300$ \\
\hline
\end{tabular}

Selain sistem pemeringkatan global, Kementerian Riset, Teknologi, dan Pendidikan Tinggi (Kemenristekdikti) Indonesia juga melakukan pemeringkatan perguruan tinggi (PT) untuk lingkup Indonesia. Pemeringkatan berfokus pada indikator atau penilaian yang berbasis output - outcome base, yaitu dengan melihat kinerja masukan dengan bobot $40 \%$ yang meliputi kinerja input (15\%) dan proses $(25 \%)$, serta kinerja luaran dengan bobot $60 \%$ yang meliputi kinerja output $(25 \%)$, dan outcome $(35 \%)$. Tabel 3 memperlihatkan klasterisasi (klaster 1/tertinggi) perguruan tinggi non-vokasi tahun 2018.

Tabel 3. Klasterisasi (Klaster 1) Perguruan Tinggi Non-Vokasi Tahun 2018

\begin{tabular}{|c|c|c|}
\hline Nama PT & Skor Total & Peringkat \\
\hline Institut Teknologi Bandung & 3.57 & 1 \\
\hline Universitas Gadjah Mada & 3.54 & 2 \\
\hline Institut Pertanian Bogor & 3.41 & 3 \\
\hline Universitas Indonesia & 3.28 & 4 \\
\hline Universitas Diponegoro & 3.12 & 5 \\
\hline
\end{tabular}




\begin{tabular}{lcc}
\hline \multicolumn{1}{c}{ Nama PT } & Skor Total & Peringkat \\
\hline Institut Teknologi Sepuluh Nopember & 3.10 & 6 \\
Universitas Airlangga & 3.03 & 7 \\
Universitas Hasanuddin & 2.99 & 8 \\
Universitas Padjadjaran & 2.95 & 9 \\
Universitas Andalas & 2.88 & 10 \\
Universitas Negeri Yogyakarta & 2.83 & 11 \\
Universitas Brawijaya & 2.82 & 12 \\
Universitas Pendidikan Indonesia & 2.70 & 13 \\
Universitas Negeri Malang & 2.61 & 14 \\
\hline
\end{tabular}

Sejak perang dunia kedua berakhir disiplin ekonomi pembangunan mulai berkembang, tujuan disiplin ini untuk menganalisis apa yang disebut ekonomi negara-negara berkembang. Model-model yang kemudian dinisbatkan sebagai pemikiran neoklasik, yang meyakini di masyarakat terjadi suatu proses harmonis yang menyebarkan manfaat pertumbuhan ekonomi ke seluruh masyarakat dalam kelembagaan yang ada, struktur sosial yang ada, dan permintaan efektif yang ada, melalui apa yang disebut mekanisme tetesan ke bawah (trickle-down mechanism), mulai ditinggalkan. Pemikiran ini tidak mempertimbangkan persoalan-persoalan sosial dalam pembangunan, seperti penyerapan tenaga kerja, kemiskinan, distribusi pendapatan dan kekayaan, dampak teknologi yang digunakan dalam proses produksi, dan kelembagaan nasyarakat yang dianggap sebagai sesuatu yang exogenous. Saat ini, terdapat beberapa faktor untuk meningkatkan pembangunan, Masino \& Niño-Zarazúa (2016) menyatakan strategi kebijakan kunci untuk meningkatkan fungsi sistem pendidikan, kualitas layanan, dan tantangan utama untuk agenda pendidikan global di masa depan, yaitu: keadilan sosial, perspektif hak asasi manusia, dan kemajuan dalam teori ekonomi yang menekankan peran modal manusia dalam pembangunan telah menjadi pusat dalam proses itu.

Menurut data Badan Pusat Statistik Indonesia tahun 2018, hampir 8.8\% dari total 7 juta lebih sarjana menganggur. Angka ini meningkat $1.13 \%$ dari tahun 2017. Sekitar 630.000 sarjana pengangguran musti berkompetensi dan keahlian tertentu dengan pekerja asing yang datang dari terbukanya globalisasi. Pendidikan tinggi sebagai lembaga pencetak sumber daya manusia yang unggul diharapkan dapat memberi kontribusi besar terhadap upaya peningkatan kapasitas sumber daya manusia. Situasi di Indonesia yang dialami India, seperti yang dikatakan Joshi \& Ahir (2019) bahwa pendidikan tinggi India harus mengatasi masalah keadilan, kualitas dan efisiensi secara pragmatis melalui kerangka kebijakan yang efektif untuk menjadi kompetitif secara global dan relevan dengan permintaan pasar tenaga kerja.

\section{METODE}

Penelitian ini bertujuan untuk melakukan penyelidikan lebih mendalam mengenai consumtion abroad, yang merupakan salah satu dampak globalisasi yang nyata, terjadi arus perpindahan konsumen pergi ke luar negeri dan berstatus bukan penduduk dimana jasa dikonsumsi, termasuk pendidikan tinggi. Penelitian ini menghubungkan praktik pendidikan tinggi di Indonesia: isu consumption abroad, perkembangan teknologi, dan perubahan kepemimpinan strategis.

Jenis penelitian ini menggunakan penelitian kepustakaan. Penelitian kepustakaan merupakan suatu penelitian yang digunakan untuk mengumpulkan berabagai macam informasi dan data dari berbagai macam materi yang tersedia di perpustakaan berupa dokumen, buku, majalah, kisah-kisah sejarah, berita, dan sebagainya. Penagambilan data diperoleh dari berbagai berita yang berasal dari artikel-artikel pada jurnal online yang berkaitan dengan dengan tema yang diteliti.

Penelusuran dari berbagai artikel yang digunakan peneliti dengan menggunakan kata kunci pendidikan tinggi, consumption abroad, perkembangan teknologi, dan perubahan kepemimpinan strategis. Metode penelitian menggunakan metode dokumentasi dengan cara mencari data mengenai hal-hal atau variabel yang berupa catatan, buku, makalah atau artikel, jurnal dan berita. Analisi data dengan cara pengujian validitas data dengan menggunakan triangulasi sumber data. Analisis data dengan dilakukan dengan tahapan pengumpulan data, reduksi data, display data, dan kesimpulan. 


\section{HASIL}

Consumtion abroad merupakan salah satu dampak globalisasi, terjadi arus perpindahan konsumen pergi ke luar negeri dan berstatus bukan penduduk dimana jasa dikonsumsi. Consumtion abroad dapat dikategorisasikan menjadi tiga fase yang berbeda, tetapi terkait. Fase pertama mengalami lonjakan arus mahasiswa lintas-batas, fase kedua melihat perkembangan pusat-pusat pendidikan dan kampus-kampus, dan fase ketiga dan yang terbaru menyaksikan mobilitas program dan direvolusi oleh massifikasi kursus online seperti kursus terbuka online. Pendidik dan lembaga pendidikan tinggi harus mengembangkan pendekatan yang berbeda untuk memenuhi semua kebutuhan pendidikan komunitas mahasiswa yang sedang tumbuh, terutama mahasiswa internasional.

Teknologi baru yang relevan dengan bidang pendidikan, pengetahuan bersifat subyektif dan metode pembelajaran difokuskan pada interaksi, partisipasi, dan dialog. Mahasiswa juga aktif dan mengambil inisiatif. Teknologi berpengaruh positif dan signifikan terhadap pertumbuhan ekonomi Indonesia. Secara simultan tingkat pendidikan dan teknologi memberikan pengaruh terhadap pertumbuhan ekonomi Indonesia.

Kepemimpinan strategis pendidikan tinggi musti menetapkan arah dengan menyusun satu visi masa depan kemudian menyatukan, mengkomunikasikan dan mengilhami orang dalam organisasi untuk mencapai tujuan tersebut. Kepemimpinan fokus pada fungsi, tugas, dan perilaku. Kepemimpinan strategis pendidikan tinggi merupakan urusan banyak orang yang terlibat langsung maupun tidak langusng. Pendidikan tinggi musti menerapkan kepemimpinan transformatif, organik, demokratik, dan transparan. Pemimpin harus bisa membangkitkan semangat dan gairah perubahan dari setiap orang di dalam perguruan tinggi untuk menyesuaikan diri dengan lebih cepat, serta berjuang dan bekerja keras untuk mendapatkan hasil perubahan yang lebih baik dari rencana yang ada.

\section{PEMBAHASAN}

Globalisasi adalah proses yang digerakkan oleh pasar dan itu berasal dari keyakinan bahwa pasar memainkan peran yang lebih penting daripada negara dalam pembangunan. Consumtion abroad merupakan salah satu dampak globalisasi, terjadi arus perpindahan konsumen pergi ke luar negeri dan berstatus bukan penduduk dimana jasa dikonsumsi. Konsumen melakukan perjalanan atau berpindah untuk mempermudah terjadinya transaksi, termasuk pula perpindahan hak milik konsumen. Seiring dengan globalisasi pendidikan, pembukaan pendidikan dihadapkan dengan peluang dan tantangan baru, yang berarti harus memiliki lebih banyak komunikasi dengan negara lain, meningkatkan kemampuan kompetitif, dan mengambil bagian aktif dari globalisasi pendidikan dengan pandangan globalisasi. Jadoon et al., (2016) menyatakan globalisasi telah mengubah pola konsumen, budaya, berperilaku, dan berpikir yang memengaruhi pilihan barang dan jasa yang dikonsumsi masyarakat dalam kehidupan rutin mereka.

Pendidikan tinggi merupakan salah satu pilihan jasa yang dikonsumsi sebagai upaya pengembangan ilmu dan kemampuan lebih baik lagi yang dilakukan dengan mencari sumber-sumber pengetahuan yang tidak terbatas. Consumtion abroad memberikan dampak terhadap praktik pendidikan tinggi antar negara, di mana jasa pendidikan dapat menjadi akses lintas batas. Lalu lintas mahasiswa diberbagai pendidikan tinggi menjadi pemandangan lumrah. Varghese (2014) menyatakan consumtion abroad dapat dikategorisasikan menjadi tiga fase yang berbeda, tetapi terkait. Fase pertama mengalami lonjakan arus mahasiswa lintas-batas, fase kedua melihat perkembangan pusat-pusat pendidikan dan kampus-kampus, dan fase ketiga dan yang terbaru menyaksikan mobilitas program dan direvolusi oleh massifikasi kursus online seperti kursus terbuka online.

Kompetisi pendidikan tinggi mendorong berbagai negara untuk mengembangkan kapasitas ilmu dan teknologi dalam berbagai praktik pengajaran. Pendidikan tinggi yang unggul diberbagai belahan negara lain menjadi incaran calon mahasiswa, dengan meninggalkan negara asalnya. Akopova \& Przhedetskaya (2015) menyatakan nilai kemajuan ilmiah dan teknis dan kemampuan untuk menerapkan teknologi baru meningkat dalam persaingan geopolitik. Sementara itu negara-negara, yang tidak dapat 
memberikan tingkat pendidikan yang diperlukan bagi warga negaranya, pengembangan ilmu pengetahuan dan kualitas lingkungan informasi, tidak dapat dihindari akan sangat tergantung pada pusat keuangan internasional, akan mempertahankan peran provinsi, sumber mentah, dan sumber daya manusia untuk perusahaan multinasional dan negara-negara yang paling menjanjikan. Jang (2017) menyatakan mereka menikmati kegiatan rekreasi seperti perjalanan dan bergaul sehari-hari, sehingga membangun versi kosmopolitanisme mereka. Harper (2016) menyatakan motivasi mahasiswa untuk belajar di luar negeri dapat dikategorikan sebagai intrinsik atau ekstrinsik dan bahwa keyakinan mahasiswa tentang studi di luar negeri berdampak pada pengembangan dan pengalaman interpersonal mereka. Mahasiswa belajar di luar negeri untuk mengembangkan secara interpersonal, untuk mengembangkan keterampilan.

Selain motivasi intrinsik atau ekstrinsik mahasiswa lintas batas, terdapat juga motif investasi dengan pengembalian di masa depan. Cebolla-Boado et al., (2018) menyatakan pengembalian pasar tenaga kerja memberikan pemahaman tentang mobilitas pelajar internasional. Katz-Gerro (2017) menyatakan kerangka kerja lintas-nasional menawarkan wawasan ke tingkat kosmopolitanisme budaya di sejumlah besar negara dan sejauh mana korelasi kosmopolitanisme budaya bertemu di berbagai negara.

Pendidikan tinggi diberbagai negara perlu menyiapkan kedatangan mahasiswa lintas batas, terutama untuk negara dengan kualitas pendidikan tinggi yang bagus. Sampai saat ini banyak negara yang masih tidak mengizinkan masuk dan berdirinya pendidikan tinggi asing, salah satu cara untuk mengatasi ketertinggalan sumber daya manusianya yaitu dengan mendorong mahasiswa lintas batas. Sarker (2015) menyatakan mengizinkan investasi asing dalam pendidikan merusak identitas nasional. Jalan tengah bisa dilakukan: meningkatkan biaya untuk mahasiswa yang makmur dan lebih banyak beamahasiswa untuk mahasiswa miskin bisa menjadi pilihan. Bagian pertama dari opsi ini sudah dipraktikkan melalui kursus profesional yang dibiayai sendiri di banyak universitas negeri di India, tetapi mahasiswa miskin tidak memiliki akses ke kursus tersebut. Bidyuk (2016) menyatakan oleh karena itu, telah disarankan bahwa pendidik dan lembaga pendidikan tinggi harus mengembangkan pendekatan yang berbeda untuk memenuhi semua kebutuhan pendidikan komunitas mahasiswa yang sedang tumbuh, terutama mahasiswa internasional.

Berbagai persiapan perlu dilakukan pendidikan tinggi untuk mengambil manfaat dari fenomena consumtion abroad. Berbagai faktor mahasiswa lintas batas untuk memilih pendidikan tinggi dapat dijadikan acuan untuk mendorong kemajuan pendidikan tinggi. Polly et al., (2015) menyatakan faktorfaktor yang mempengaruhi keputusan untuk mendaftar di berbagai institusi luar negeri yaitu meningkatkan pengalaman pribadi, membangun kontak internasional, dan membangun jaringan profesional. Faktorfaktor kunci yang mempengaruhi pilihan negara tuan rumah yaitu prospek pekerjaan bergaji tinggi setelah lulus, infrastruktur dan fasilitas publik yang lebih baik, program pendidikan internasional yang mapan yang diakui secara internasional, pengakuan gelar saat ini untuk pekerjaan dan pendidikan lanjutan, dan kemudahan akses ke informasi. Landon et al., (2017) menyatakan cukup bepergian ke luar negeri dan berpartisipasi dalam program studi di luar negeri tidak serta merta menghasilkan hasil belajar yang diinginkan. Nguyen \& Coryell (2015) menyatakan tema yang lazim dalam penelitian yang hadir untuk mempelajari partisipasi di luar negeri berfokus pada sosial, kelembagaan, akademik, alasan pribadi, dan keuangan.

Kemajuan teknologi semakin kencang lajunya, setelah munculnya teknologi baru the Fourth Industrial Revolution (4IR) dan the Fifth Generation (5G) yaitu wireless communication technology dan segera disusul the Sixth Generation (6G). Perkembangan teknologi memasuki era dimana teknologi baru menjadi kebutuhan dalam pengajaran di perguruan tinggi. Rajesh (2015) menyatakan teknologi baru yang relevan dengan bidang pendidikan, pengetahuan bersifat subyektif dan metode pembelajaran difokuskan pada interaksi, partisipasi, dan dialog. Mahasiswa juga aktif dan mengambil inisiatif. Willis et al., (2020) menyatakan teknologi digital sangat terintegrasi ke dalam sistem pendidikan kita; sekolah beroperasi pada konektivitas jaringan dan sangat bergantung pada internet. Crittenden \& Peterson (2019) menyatakan teknologi digital berkontribusi terhadap perubahan besar dalam praktik, janji, dan operasi pendidikan tinggi, dan perubahan ini menantang pendidikan tinggi untuk berinovasi dan untuk menyegarkan program dan desain kurikulum. Al-Imarah \& Shields (2019) menyatakan Massive Open Online Courses (MOOCs) pada pendidikan tinggi merupakan inovasi berkelanjutan yang membangun pasar baru untuk pelajar yang tidak dilayani oleh universitas. 
Di Indonesia, pertumbuhan ekonominya dipengaruhi oleh tingkat pendidikan dan teknologi, keduanya bertemu di dalam kelas pengajaran dan pembelajaran. Pendidikan tinggi memiliki peran strategis terhadap pertemuan pendidikan dan teknologi dalam kelas pengajaran dan pembelajaran tersebut. Lucya \& Anis (2019) menyatakan tingkat pendidikan berpengaruh positif dan signifikan terhadap pertumbuhan ekonomi Indonesia. Teknologi berpengaruh positif dan signifikan terhadap pertumbuhan ekonomi Indonesia. Secara simultan tingkat pendidikan dan teknologi memberikan pengaruh terhadap pertumbuhan ekonomi Indonesia.

Sayangnya kemajuan teknologi tidak serta merta diikuti oleh pendidikan tinggi. Berbagai macam hambatan masih dihadapi pendidikan tinggi, termasuk di Indonesia. Kearney et al., (2019) menyatakan semakin banyak bukti menunjukkan bahwa pedagogi tradisional masih mendominasi bidang pendidikan dan tidak selaras dengan beragam kesempatan belajar yang ditawarkan oleh penggunaan teknologi seluler. Bond et al., (2019) menyatakan evolusi pengajaran dan pembelajaran dalam pendidikan jarak jauh, munculnya desain pengajaran, kesalahpahaman antara praktisi dan desainer pembelajaran, masalah pendidikan guru pra dan dalam layanan dan penyerapan teknologi oleh pendidik dan mahasiswa, termasuk kepercayaan diri untuk melakukannya, keterampilan teknologi para pendidik dan mahasiswa, serta kurangnya dukungan kelembagaan untuk menyediakan ruang dan waktu untuk pelatihan dan integrasi terjadi.

Modal positif dimiliki oleh mahasiswa diberbagai perguruan tinggi di Indonesia terhadap berbagai kemajuan teknologi tampak dalam kebiasaan belajar mereka. Aslamiyah (2019) menyatakan kemandirian belajar mahasiswa Indonesia berada pada kategori positif, yang tampak pada ketidaktergantungan terhadap orang lain, berperilaku disiplin, dan berperilaku berdasarkan inisiatif sendiri.

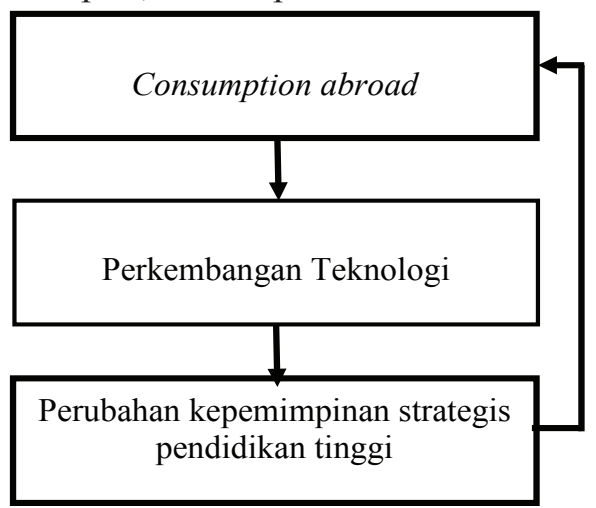

Gambar 1 Hubungan Antar Faktor Kepemimpinan Strategis Pendidikan Tinggi

Isu consumption abroad dan perkembangan teknologi, membawa pengaruh terhadap perubahan kepemimpinan strategis pendidikan tinggi. Kepemimpinan strategis pendidikan tinggi mampu melihat berbagai perubahan sebagai upaya kepemimpinan berkaitan dengan penanganannya. Kepemimpinan strategis pendidikan tinggi musti menetapkan arah dengan menyusun satu visi masa depan kemudian menyatukan, mengkomunikasikan dan mengilhami orang dalam organisasi untuk mencapai tujuan tersebut. Upaya tersebut dilakukan untuk mengelola akibat-akibat yang ditimbulkan karena terjadinya perubahan dalam organisasi. Perubahan dapat terjadi karena sebab-sebab yang berasal dari dalam maupun dari luar organisasi tersebut. Khan (2017) menyatakan institusi pendidikan tinggi beroperasi dalam lingkungan yang kompleks yang mencakup pengaruh dari faktor-faktor eksternal, teknologi baru untuk pengajaran dan pembelajaran, globalisasi, dan perubahan demografi mahasiswa. Manuver kompleksitas dan perubahan seperti itu membutuhkan strategi kepemimpinan yang fleksibel dan mendukung. Gambar 1 menjelaskan hubungan berbagai faktor-faktor yang berpengaruh terhadap perubahan kepemimpinan strategis pendidikan tinggi tersebut.

Untuk mendorong kepemimpinan starategis pendidikan tinggi yang memiliki kualitas bagus perlu upaya yang keras dalam menghadapi berbagai tantangan dan implikasi perkembangan ilmu, praktik, dan penelitian. Pucciarelli \& Kaplan (2016) menyatakan tiga tantangan inti pendidikan tinggi menghadapi dan yang memiliki implikasi mendasar untuk penelitian dan praktik: (1) kebutuhan untuk meningkatkan 
prestise dan pangsa pasar; (2) kebutuhan untuk merangkul pola pikir kewirausahaan; dan (3) kebutuhan untuk memperluas interaksi dan menghargai penciptaan bersama dengan para pemangku kepentingan utama.

Melalui kepemimpinan startegis pendidikan tinggi, kegiatan manajerial dapat dilakukan lebih efektif. Kepemimpinan fokus pada fungsi, tugas, dan perilaku. King \& Boyatt (2015) menyarankan pentingnya strategi kelembagaan yang ditargetkan untuk menyediakan sumber daya dan panduan yang memadai untuk implementasi yang efektif. Strategi ini perlu didukung oleh program pengembangan staf yang beragam dan peluang untuk berbagi praktik di antara rekan kerja. Dalam mengembangkan pemahaman lebih lanjut dalam bidang ini, bermanfaat untuk mereplikasi penelitian dengan kelompok pemangku kepentingan lainnya (termasuk tim kepemimpinan dan mahasiswa) untuk mengembangkan strategi kelembagaan yang responsif di semua tingkat implementasi. Penting juga untuk menyelidiki sejauh mana temuan ini direplikasi di tempat kerja lain yang ingin mengadopsi inovasi.

Kepemimpinan strategis pendidikan tinggi merupakan urusan banyak orang yang terlibat langsung maupun tidak langusng. Setiap pemimpin berkewajiban melakukan pertanggungjawaban atas kepemimpinannya. Gonzales (2019) menyatakan terdapat 5 filosofi kepemimpinan pendidikan yaitu esensialisme, perenialisme, progresivisme, behaviorisme, atau eksistensialisme (The Five KeyEducation). Barbuto \& Davoudpour (2019) mengkonfirmasi perbedaan generasi dalam gaya kepemimpinan. Bracht et al., (2018) menyatakan hingga saat ini, konsep kepemimpinan difokuskan pada pencapaian tujuan tingkat individu atau tim, dan dengan demikian tidak sepenuhnya dapat diterapkan pada konteks sosialorganisasi yang lebih luas. Ncube (2010) menyatakan kepemimpinan adalah tentang pengetahuan, keterampilan, dan kemampuan untuk transformasi.

Kepemimpinan strategis pendidikan tinggi perlu memadukannya dengan aktifitas manajemen yang baik. Peran kepemimpinan strategis pendidikan tinggi tidaklah signifikan terhadap perubahan organisasi, tidak ada artinya jika tanpa didukung oleh seluruh jenjang manajemen. Slamet (2019) menyatakan selain manajemen, untuk mengeksekusi visi, misi, tujuan, strategi, kebijakan, dan program-programnya, jika ingin melesatkan mutunya, pendidikan tinggi harus menerapkan kepemimpinan transformatif, organik, demokratik, dan transparan. Kalau manajemen lebih menekankan pada technical side, maka kepemimpinan lebih menekankan pada socio-culture side (human side).

Pemahaman terhadap keberagaman sangat penting dalam kepemimpinan strategis pendidikan tinggi. Lumby \& Foskett (2016) menyatakan kepemimpinan internasionalisasi yang dipertimbangkan dan berhati-hati, menjaga kekhasan dan mempromosikan kesetaraan di antara budaya adalah kepentingan komersial jangka panjang dari universitas, serta menawarkan manfaat individu dan sosial. Adserias et al., (2018) menyatakan kepemimpinan strategis pendidikan tinggi perlu menerapkan agenda keberagaman di dalam lembaga yang terdesentralisasi, longgar, dan tahan perubahan seperti perguruan tinggi dan universitas adalah tantangan global. Pergeseran dalam iklim dan budaya organisasi sangat penting untuk menghasilkan perubahan yang dibutuhkan agar agenda keragaman dapat berkembang. Sarjana pendidikan tinggi telah secara konsisten mengidentifikasi gaya kepemimpinan sebagai salah satu faktor utama yang berkontribusi terhadap perubahan kelembagaan yang sukses, terutama yang berkaitan dengan upaya agenda keberagaman.

Tugas kepemimpinan strategis pendidikan tinggi di tengah berbagai perubahan consumption abroad, perkembangan teknologi, dan politik pendidikan domestik, merupakan kunci dari keberhasilan sebuah perubahan besar dalam organisasi pendidikan. Pemimpin harus memiliki kredibilitas dan reputasi yang baik, agar mampu memberikan inspirasi dan motivasi kepada setiap orang. Memotivasi dan menginspirasi setiap orang dalam kehidupan mereka, untuk bersemangat dan bangkit bersama dengan perubahan baru. Membuat setiap orang menyadari bahwa perubahan itu penting, untuk mengubah hal-hal yang tertinggal zaman dengan hal-hal baru yang sesuai peradaban. Pemimpin harus bisa membangkitkan semangat dan gairah perubahan dari setiap orang di dalam perguruan tinggi untuk menyesuaikan diri dengan lebih cepat, serta berjuang dan bekerja keras untuk mendapatkan hasil perubahan yang lebih baik dari rencana yang ada. Pemimpin harus menyadarkan setiap orang, agar selalu menggunakan cara-cara profesionalisme dalam merespon setiap perubahan. Untuk itu, pimpinan pendidikan tinggi harus duduk 
bersama semua kekuatan sumber daya manusianya, untuk berbicara tentang perubahan-perubahan itu dengan cara-cara penuh inspirasi dan profesional. Pemimpin memiliki kemampuan untuk mengajak dan menggandeng setiap hati dan setiap pikiran, untuk berpikir dan bertindak dalam semangat meningkatkan semua potensi perguruan tinggi, agar mampu menangani semua potensi yang dimiliki secara lebih baik, dengan cara mengubah hal-hal yang menghambat gerak sukses perguruan tinggi.

\section{SIMPULAN}

Pendidikan tinggi Indonesia harus mengatasi masalah consumption abroad, perkembangan teknologi, dan kepemimpinan secara pragmatis melalui perubahan kepemimpinan strategis yang efektif untuk menjadi kompetitif secara global dan relevan dengan permintaan pasar tenaga kerja. Seiring dengan globalisasi pendidikan, pembukaan pendidikan dihadapkan dengan peluang dan tantangan baru, yang berarti kita harus memiliki lebih banyak komunikasi dengan negara lain, meningkatkan kemampuan kompetitif, dan mengambil bagian aktif dari globalisasi pendidikan dengan pandangan globalisasi. Kepemimpinan strategis pendidikan tinggi musti mampu melihat berbagai perubahan sebagai upaya kepemimpinan berkaitan dengan penanganannya. Kepemimpinan strategis pendidikan tinggi dapat menetapkan arah dengan menyusun satu visi masa depan kemudian menyatukan, mengkomunikasikan dan mengilhami orang dalam organisasi untuk mencapai tujuan tersebut. Untuk mendorong kepemimpinan starategis pendidikan tinggi yang memiliki kualitas bagus perlu upaya yang keras dalam menghadapi berbagai tantangan dan implikasi perkembangan ilmu, praktik, dan penelitian.

\section{REFERENCE}

Adserias, R., Charleston, L., \& Jackson, J. (2018). What style of leadership is best suited to direct organizational change to fuel institutional diversity in higher education? (pp. 26-42). https://doi.org/10.4324/97804294442343

Akopova, E., \& Przhedetskaya, N. (2015). Institutional designing of continuous education in Russia under the conditions of neo-economy and globalization. Regional and Sectoral Economic Studies, 15(2), 115-122.

Al-Imarah, A. A., \& Shields, R. (2019). MOOCs, disruptive innovation and the future of higher education: A conceptual analysis. Innovations in Education and Teaching International, 56(3), 258-269. https://doi.org/1 $0.1080 / 14703297.2018 .1443828$

Aslamiyah, T. A. (2019). Blended Learning dan Kemandirian Belajar Mahasiswa Teknologi Pendidikan. SKRIPSI Jurusan Teknologi Pendidikan - Fakultas Ilmu Pendidikan UM, O(0), Article 0. http://karya-ilmiah.um.ac.id/ index.php/TEP/article/view/82058

Barbuto, J. E., \& Davoudpour, S. (2019). Servant Leadership Philosophy Across Intergenerational Cohorts: An Empirical Inquiry. Academy of Management Proceedings, 2019(1), 11539. https://doi.org/10.5465/ AMBPP.2019.11539abstract

Bidyuk, N. (2016). Higher Education Globalization in the Context of American Guidelines. Comparative Professional Pedagogy, 6(4), 7-14. https://doi.org/10.1515/rpp-2016-0041

Bond, M., Zawacki-Richter, O., \& Nichols, M. (2019). Revisiting five decades of educational technology research: A content and authorship analysis of the British Journal of Educational Technology. British Journal of Educational Technology, 50(1), 12-63.

Bracht, E. M., Junker, N. M., \& Dick, R. van. (2018). Exploring the social context of self-leadership-Selfleadership-culture. Journal of Theoretical Social Psychology, 2(4), 119-130. https://doi.org/10.1002/jts5.33

Cebolla-Boado, H., Hu, Y., \& Soysal, Y. N. (2018). Why study abroad? Sorting of Chinese students across British universities. British Journal of Sociology of Education, 39(3), 365-380. https://doi.org/10.1080/01425692.2 017.1349649

Crittenden, V., \& Peterson, R. A. (2019). Digital Disruption: The Transdisciplinary Future of Marketing Education. Journal of Marketing Education, 41(1), 3-4. https://doi.org/10.1177/0273475319825534

Gonzales, S. R. (2019). A Leg to Stand On: Developing Core Beliefs and a Leadership Philosophy for Sound Ethical Decision-Making. New Directions for Community Colleges, 2019(185), 43-51. https://doi.org/10.1002/ cc. 20337 
Harper, J. S. (2016). Extrinsic and intrinsic motivations and their impact on student participation in a study abroad experience. https://tu-ir.tdl.org/handle/2346/72368

Jadoon, A. K., Butt, A. R., \& Hayat, M. A. (2016). Development of Measurement Models for Globalization, Consumption Patterns and Culture: A Case Study of Three Big Cities of Punjab, Pakistan. Pakistan Economic and Social Review, 54(2), 327-361.

Jang, I. C. (2017). Consuming Global Language and Culture: South Korean Youth in English Study Abroad [Thesis]. https://tspace.library.utoronto.ca/handle/1807/79006

Joshi, K. M., \& Ahir, K. V. (2019). Higher Education in India: Issues related to Access, Equity, Efficiency, Quality and Internationalization. Academia, 0(14), 70-91. https://doi.org/10.26220/aca.2979

Katz-Gerro, T. (2017). Cross-National Differences in the Consumption of Non-National Culture in Europe. Cultural Sociology, 11(4), 438-467. https://doi.org/10.1177/1749975517725637

Kearney, M., Burden, K., \& Schuck, S. (2019). Disrupting Education Using Smart Mobile Pedagogies. In L. Daniela (Ed.), Didactics of Smart Pedagogy: Smart Pedagogy for Technology Enhanced Learning (pp. 139157). Springer International Publishing. https://doi.org/10.1007/978-3-030-01551-0_7

Khan, N. (2017). Adaptive or Transactional Leadership in Current Higher Education: A Brief Comparison. International Review of Research in Open and Distributed Learning, 18(3), 178-183. https://doi.org/10.19173/ irrodl.v18i3.3294

King, E., \& Boyatt, R. (2015). Exploring factors that influence adoption of e-learning within higher education. British Journal of Educational Technology, 46(6), 1272-1280.

Landon, A. C., Tarrant, M. A., Rubin, D. L., \& Stoner, L. (2017). Beyond “Just Do It": Fostering Higher-Order Learning Outcomes in Short-Term Study Abroad. AERA Open, 3(1). https://eric.ed.gov/?id=EJ1194154

Lucya, C., \& Anis, A. (2019). Pengaruh Teknologi dan Pendidikan Terhadap Pertumbuhan Ekonomi Di Indonesia. Jurnal Kajian Ekonomi Dan Pembangunan, 1(2), 509-518. https://doi.org/10.24036/jkep.v1i2.6261

Lumby, J., \& Foskett, N. (2016). Internationalization and Culture in Higher Education. Educational Management Administration \& Leadership, 44(1), 95-111. https://doi.org/10.1177/1741143214549978

Masino, S., \& Niño-Zarazúa, M. (2016). What works to improve the quality of student learning in developing countries? International Journal of Educational Development, 48, 53-65. https://doi.org/10.1016/j. ijedudev.2015.11.012

Ncube, L. B. (2010). Ubuntu: A transformative leadership philosophy. Journal of Leadership Studies, 4(3), 77-82. https://doi.org/10.1002/jls.20182

Nguyen, S., \& Coryell, J. E. (2015). Flipping the Script in Study Abroad Participation: The Influence of Popular Culture and Social Networks. Journal of International Students, 5(1), 23-37.

Oude Vrielink, R. A., Jansen, E. A., Hans, E. W., \& van Hillegersberg, J. (2019). Practices in timetabling in higher education institutions: A systematic review. Annals of Operations Research, 275(1), 145-160. https://doi. org/10.1007/s10479-017-2688-8

Polly, D., McGee, J., Wang, C., Martin, C., Lambert, R., \& Pugalee, D. K. (2015). Linking professional development, teacher outcomes, and student achievement: The case of a learner-centered mathematics program for elementary school teachers. International Journal of Educational Research, 72, 26-37. https:// doi.org/10.1016/j.ijer.2015.04.002

Pucciarelli, F., \& Kaplan, A. (2016). Competition and strategy in higher education: Managing complexity and uncertainty. Business Horizons, 59(3), 311-320. https://doi.org/10.1016/j.bushor.2016.01.003

Rajesh, M. (2015). Revolution in Communication Technologies: Impact on Distance Education. Turkish Online Journal of Distance Education, 16(1), 62-88. https://doi.org/10.17718/tojde.26353

Sarker, K. (2015). Neoliberalism, GATS, and Higher Education in India: Moving Away from Its Original Objectives. New Proposals: Journal of Marxism and Interdisciplinary Inquiry, 7(2), 13-27.

Slamet, S. (2019). Melesatkan Mutu Pendidikan Tinggi Di Era Terpori (Disampaikan pada Acara Pelepasan Pegawai Negeri Sipil dengan Jabatan Akademik Guru Besar). http://baki.uny.ac.id/news/melesatkan-mutupendidikan-tinggi-di-era-terpori

Varghese, N. V. (2014). Globalization and higher education: Changing trends in cross border education. 5, 7-20.

Willis, J., Krausen, K., \& Outlaw, L. (2020). Managing Public Education Resources during the Coronavirus Crisis: Practical Tips and Considerations for School District Leaders. Crisis Response Resource. In WestEd. WestEd. https://eric.ed.gov/?id=ED605941 